\title{
A contribuição do homem simples na construção da esfera pública: os trabalhadores rurais de Baturité - Ceará*
}

\author{
Sônia Pereira
}

Universidade Federal do Ceará, Faculdade de Educação

\section{Introdução}

Este artigo examina questões relacionadas à política e às formas participativas construídas pela sociedade civil brasileira, em particular pelos trabalhadores rurais do Nordeste do Brasil. O exame de várias questões se fez em torno de uma indagação tomada de empréstimo da socióloga Vera da Silva Telles (1994, 1999), assim formulada: numa sociedade como a brasileira, atravessada por ambigüidades, pode a cidadania se enraizar nas práticas sociais? Buscando analisar aspectos da realidade que me permitiram formular interpretações acerca da problemática da participação e da política, o artigo está estruturado em duas partes. $\mathrm{Na}$ primeira, que se intitula "Construindo uma com-

* Artigo produzido a partir de pesquisa para a tese de doutorado que, com o mesmo título, foi defendida em setembro de 2002, no Programa de Estudos Pós-Graduados em Ciências Sociais da PUC-SP e apresentado no GT Educação e Movimentos Sociais, na 26a Reunião Anual da ANPEd, realizada em Poços de Caldas, MG, de 5 a 8 de outubro de 2003. preensão da política e da esfera pública", efetuo uma sistematização das questões que conduziram a reflexão e a metodologia construída na experiência investigativa. A segunda parte, denominada "A política vivenciada pelo trabalhador rural nos espaços públicos: a esfera pública em construção", traz uma análise bastante resumida das experiências participativas; possui caráter conclusivo, em função da necessidade de atender às limitações do espaço de um artigo.

\section{Construindo uma compreensão da política e da esfera pública}

A pesquisa teve início a partir de uma pergunta básica: qual o significado da política na sociedade contemporânea? Como o homem comum - homem simples, personagem anônimo das pequenas e grandes cidades - concebe e vivencia a política?

Como atua politicamente esse homem simples, [...] que não só luta para viver todo dia, mas que luta para compreender um viver que lhe escapa porque não raro se apresenta como absurdo, como se fosse um viver destituído de sentido (Martins, 2000, p. 11). 
Para analisar tal questão, não se pode desconsiderar os termos em que se efetivaram a política e a participação social no Brasil, nas últimas décadas. Para Carvalho (1997), a participação emerge e se caracteriza como oferta do Estado e como conquista da sociedade civil e dos movimentos sociais. Oferta do Estado quando este se propõe a administrar as políticas públicas, de forma descentralizada; e conquista da sociedade civil na medida em que esta ocupou e construiu espaços em uma sociedade cujas elites buscaram tradicionalmente manter os movimentos sociais alijados dos processos decisórios, nos vários momentos da história política nacional.

A política, no entanto, vem sofrendo redefinições. Mudanças ocorrem tanto no contexto em que ela se exercita quanto no seu próprio conceito, pois a sociedade vem encontrando novas formas de se expressar politicamente, além de buscar redefinir as formas tradicionais, como partidos, parlamentos etc., legados da democracia liberal. Com base em Rancière (1996), pode-se dizer, de forma breve, que "a política é o rompimento do consenso" através da fala, da reivindicação; é conflito, dissenso ou consenso negociado, processo que indica mudança de lugares sociais. $\mathrm{O}$ exercício da política possibilita ao homem simples a construção de processos que, na relação do Estado com a sociedade civil, publicizam carências e necessidades, além de afirmarem direitos. A esfera pública se constrói, então, como a dimensão política fundada na idéia do conflito e da negociação, envolvendo a representação de interesses coletivos na cena pública. Em outros termos, a interlocução do Estado com a sociedade civil inaugura processos que o tornam mais transparente e que estão direcionados para a afirmação de direitos universais, deslocando práticas tradicionais pautadas em privilégios e em interesses corporativos.

O protagonista deste estudo é o trabalhador rural - pequeno proprietário ou não proprietário (arrendatário, posseiro, morador) - e suas formas próprias de organização como conselhos, associações e sindicatos. A pesquisa teve início em 1997 e, após interrupção para o cumprimento de créditos no doutora- do, foi retomada e reorientada, estendendo-se, inclusive com trabalho de campo, até março de 2002.

No processo de sistematização, com base em pontos de vista de autores como Oliveira $(1995,1998$, 1999), a seguinte hipótese - no sentido de afirmação provisória (Minayo, 1999) - foi formulada: a política e a esfera pública têm se construído, no Brasil, graças aos esforços imensos das classes dominadas. $\mathrm{O}$ estudo considera, igualmente, a seguinte pressuposição: o Estado, que deveria instaurar a referência simbólica a partir da qual os indivíduos se reconheceriam como iguais, independentemente de vínculos familiares e pessoais, tem sido um personagem bastante presente na condução dos processos decisivos e decisórios e, sistematicamente, vem sendo utilizado pelas elites como instrumento privado, voltado principalmente para o atendimento de interesses particulares.

Tomando tal hipótese e pressuposição como eixo orientador, registro aqui algumas questões que passaram a dar conformação ao objeto de estudo. São as seguintes:

a. Quem são os homens e as mulheres que se empenham nas atividades comunitárias, sindicais ou em outras formas de convivência associativa? Como vivem? Quais sonhos acalentam suas vidas tão carentes de confortos do "progresso"?

b. Em que medida as ações cotidianas nos espaços públicos podem encerrar potencialidades transformadoras? Em que medida os espaços em questão contribuem para alargar as possibilidades de acesso aos recursos públicos ou tornar o trânsito do fundo público mais visível na burocracia estatal, e dessa forma ampliar a capacidade da sociedade civil de exercer o controle social sobre as políticas públicas?

c. Até que ponto as heranças culturais podem ser traços impeditivos de uma nova sociabilidade política, baseada nas noções de justiça e de solidariedade? Quais formas assumem e em quais situações o clientelismo político, a cordialidade ou as relações de simpatia ou afetivas, marcas da cultura política, se revelam? Esta- 
riam tais marcas culturais configurando e contribuindo para um "engessamento" das iniciativas participativas? Qual a importância ou a dimensão que o Estado imprimiu à experiência participativa? Que grau de publicização a experiência em estudo logrou alcançar?

A pesquisa foi realizada em Baturité (Ceará), município de 30 mil habitantes, dos quais 9 mil são trabalhadores rurais. Baturité é um município comum, com problemas comuns aos milhares de municípios nordestinos, e que tem a singularidade de possuir uma sociedade civil inquieta, atuante, embora atravessada pelas fragilidades e pelas contradições características de toda a sociedade civil brasileira. Nos anos de 1990 foram criados, aí, 12 conselhos municipais; convivem com esses conselhos 62 associações de moradores e de pequenos agricultores; e os trabalhadores rurais encontram apoio e se organizam, também, no Sindicato dos Trabalhadores Rurais, que registra em seu cadastro 5 mil sócios, sendo aproximadamente 2 mil o número de filiados ativos (que contribuem financeiramente e participam das atividades cotidianas da entidade).

A investigação, de cunho participante, foi conduzida de forma dialógica (D’Incao \& Roy, 1995) e com base na observação sistemática desses três espaços públicos - conselhos municipais, associações de pequenos agricultores e o Sindicato -, levando em consideração o fato de que o conselheiro pode ser um sindicalista, que por sua vez é uma liderança comunitária que atua na associação. O trânsito dessas experiências, curioso e rico, foi acompanhado sistematicamente pela pesquisa. Foram realizadas 33 entrevistas com sindicalistas, lideranças comunitárias (não-sindicais), lideranças políticas (prefeito, vereadores), religiosos, sócios das associações, conselheiros governamentais e não-governamentais, dois grupos de mulheres, um médio proprietário (maior produtor de milho do Município) e um grande proprietário de terras.

A observação fez-se com base em encontros de formação política e religiosa, assembléias, reuniões, greves e negociações com o governo municipal, manifestações políticas, processos eleitorais, além das entrevistas e das conversas informais - sempre ricas fontes de informação. Buscou-se - com entrevistas orientadas para a produção de relatos de vida, que propiciam a apreensão dos vários mundos - elaborar certa composição dos personagens em cena, ou seja, figuras que me permitissem reconstruir as relações sociais e políticas, encarnando-as em pessoas, como sugere o historiador inglês Thompson $(1981,1987)$.

Para aprofundamento da análise, a observação desenvolveu-se a partir do acompanhamento sistemático de duas associações: a Associação de Pequenos Agricultores Manos Kolping, cujas lutas consolidaram algumas conquistas num percurso de cerca de 15 anos; e a Associação de Pequenos Agricultores do Sítio São Pedro, mais jovem, cuja existência alcançava pouco mais de dois anos. Outras associações foram observadas, porém, com acompanhamento menos sistemático. Vali-me, também, de atas de conselhos e de artigos de periódicos (como o jornal $O$ Povo, de Fortaleza, e a Folha de S. Paulo) para o levantamento de dados.

O estudo procurou movimentar conceitos que permitissem compreender a experiência participativa do homem simples no sentido da construção da esfera pública, considerando a cultura política brasileira autoritária, atravessada por ambigüidades e ambivalências e pelo clientelismo, e caracterizada pela cordialidade, segundo os termos de Sérgio Buarque de Holanda (1984). Assim, procurei articular teórica e empiricamente conceitos como política, homem simples, esfera pública e publicização, experiência e senso comum, cotidiano, cidadania, democracia e direitos.

Não pretendo, com base em um estudo de caso, generalizar afirmações sobre a política e a esfera pública brasileira. É possível, sim, tomar tal experiência como uma, dentre centenas que estão sendo vividas pelos brasileiros, capaz de revelar aspectos singulares e aspectos que se repetem e, assim, contribuir, em alguma medida, para a ampliação do conhecimento que se vem produzindo sobre a cidadania. 


\section{A política vivenciada pelo trabalhador rural nos espaços públicos: a esfera pública em construção}

Os conselhos, as associações e o Sindicato de Trabalhadores Rurais são, em Baturité, espaços com histórias e funções próprias que, no entanto, em diversos momentos parecem exercer o mesmo papel, num entrelaçamento de práticas e aspirações.

As trajetórias das associações e do Sindicato, em especial, indicam que tais espaços mantêm uma relação, por assim dizer, orgânica com o homem comum. Cada associação tem um caminho próprio, que indica maior ou menor capacidade organizativa. A presença dos trabalhadores rurais na vida cotidiana das associações, assim como no Sindicato, imprime uma dinâmica na vida comunitária que sugere serem esses espaços terrenos próprios da população associada (ou que foram por ela "apropriados"). O percurso dos conselhos - espaços criados mais recentemente e marcados por descontinuidades - oferece, por seu lado, elementos que permitem uma avaliação diferente: são espaços ainda pouco enraizados na vida dos cidadãos e dos trabalhadores rurais, em particular.

Os conselhos municipais não têm visibilidade suficiente que denote existir do lado da sociedade civil e dos trabalhadores rurais uma compreensão acerca de sua importância como mecanismo de democratização das políticas que afetam a vida municipal. As mobilizações políticas dos anos de 1980 que asseguraram a inserção de conselhos na Constituição de 1988 - expressão do momento favorável aos movimentos sociais na correlação de forças políticas no processo de democratização da sociedade brasileira parecem fazer parte de uma memória que foi engolida por um processo de institucionalização burocrática. Os cidadãos vivem, então, as consequiências de decisões tomadas de formas não-democráticas, centralizadas na autoridade imperial ou paternalista do prefeito ou do governo estadual ou homologadas por conselhos que operam, sobretudo, como apêndices do Executivo. Este, por sua vez, usualmente é brindado com a conivência de uma câmara de vereadores tam- bém domesticada pelos vícios da cultura política tradicional.

Não obstante o débil enraizamento, os conselhos viabilizam situações nas quais o trabalhador rural percebe-se como pessoa pública, entre pares, descolando-se do invólucro privado ao encontrar mecanismos de participação e de aprendizados. Assim se expressou um trabalhador rural, representante da associação de sua comunidade no Conselho Municipal de Desenvolvimento Sustentável (CMDS): "Eu não sabia nada, não entendia nada. Aí foi indo, foi indo... um dia aquela palavra veio".

A vocalização de necessidades permite o aprendizado da fala política quando exercida em espaços públicos. As práticas tradicionais - hegemônicas, porém não absolutas na cena política - são compelidas a conviver com a presença de sujeitos que as questionam, interpelam autoridades governamentais. Esses homens e essas mulheres do campo e da cidade inauguram processos que tornam demandas o que eram carências, afirmando, assim, que são sujeitos de direitos.

De modo geral, todas essas experiências têm curta história. Sugerem, todavia, serem portadoras de possibilidades participativas alvissareiras de se tornarem mecanismos genuínos de participação, estabelecendo relações mais democráticas na vida municipal e na vida dos trabalhadores rurais. Não porque à sociedade civil atribui-se uma virtude intrínseca que, num raciocínio maniqueísta, emprestaria ao Estado um caráter intrinsecamente negativo. As perspectivas positivas devem-se, na verdade, à emergência e à persistência de processos participativos que, embora se revelem experiências incompletas ou descontínuas, persistem no tempo (historicamente curto, é verdade), impondo aprofundamentos e reorientações.

São experiências ou práticas, em alguma medida, inovadoras, porque baseadas em relações mais democráticas, valorizadoras da busca de soluções coletivas - e não somente particulares - para os problemas cotidianos do homem simples.

É certo que as relações tradicionais são repostas. No entanto, não seria adequada a consideração 
pura e simples de que há na política uma reposição constante de práticas tradicionais, clientelistas, marcadas pela cordialidade, característica de nossa cultura política. A análise aqui empreendida encontrou situações reveladoras da efetiva contribuição da sociedade (e dos movimentos sociais) para a mudança das relações sociais que caracterizavam, há três ou quatro décadas, a sociedade brasileira e a rural, em particular. É o caso, por exemplo, do controle social sobre os recursos do Fundo de Manutenção e Desenvolvimento do Ensino Fundamental e de Valorização do Magistério (FUNDEF), que conselheiros especialmente os representantes dos trabalhadores rurais e dos funcionários municipais - buscaram exercer. Avaliou-se, no Conselho Municipal de Educação, que as contas da administração municipal não estavam adequadas, pois os professores suspeitavam que os recursos do FUNDEF não tiveram utilização correta. O Conselho solicitou providências ao Ministério Público, que, por sua vez, procedeu a uma apuração. Essa apuração não detectou as supostas irregularidades. Nesse processo, porém, exigiu-se do prefeito a prestação de contas ao Conselho, além da discussão pública das questões relacionadas ao FUNDEF na emissora radiofônica local, cuja audiência é significativa tanto na sede do Município quanto nas comunidades rurais. É pouco, dirão alguns. É novo, dirão outros. Compartilho do segundo ponto de vista. Levando-se em conta o longo período de absoluta privatização do público, essas iniciativas singelas têm expressão potencializada. Se entendermos que uma gestão, para ser efetivamente pública, deve delinear-se com base na democracia, na universalidade e na transparência das decisões, conclui-se que o processo descrito acima não se configura como efetivo controle social. O controle ainda é insuficiente, ou pouco eficiente. Mas é perseguido pela sociedade civil, em especial com a representação de trabalhadores rurais e de funcionários públicos municipais.

As experiências em estudo apontam, por sua vez, para a urgência e exigência a seguir: é mister a efetiva inserção e militância da sociedade civil no esforço para desprivatizar o que deveria ser, por vocação, pú- blico - os conselhos, as associações, os sindicatos de trabalhadores rurais e o próprio Estado - engendrando efetiva ampliação deste último.

A análise da experiência de participação nos conselhos, nas associações e no Sindicato, em Baturité, pôde atestar que a presença dos cidadãos, sobretudo dos trabalhadores rurais, tem sido "a pedra no meio do caminho" do Executivo. Esse incômodo que os trabalhadores rurais provocam deve-se ao esforço que, com maior ou com menor dificuldade, empreendem, despontando na realidade local como principal personagem a tentar assegurar que o fundo público não seja desviado para o atendimento de interesses particulares.

A participação dos trabalhadores rurais em conselhos está mais direcionada para o CMDS, pois é nesse conselho que se define a distribuição de recursos financeiros oriundos do Projeto São José, um grande programa governamental cujas políticas ou linhas de ação são relativas ao campo. Os trabalhadores participam também, mas com menor frequiência, das reuniões convocadas para os conselhos setoriais ou gestores de outras políticas - de educação, saúde, trabalho, até mesmo de agricultura, pois é lá, no CMDS, que os recursos se encontram em pauta. Portanto, os conselheiros mais presentes nos conselhos municipais são os representantes da sociedade civil e do Estado na sede do Município.

Dona Maria, por exemplo, há muito já não vive na zona rural; é funcionária pública municipal e militante em seu sindicato. Já foi conselheira governamental e recentemente representa sua categoria no Conselho da Infância e Adolescência. Antes, porém, fora membro do Conselho de Saúde e do Conselho de Educação, e sua atuação se caracteriza como bastante questionadora. Colocou e coloca em questão não somente valores e recursos financeiros, mas a forma de representantes governamentais atuarem politicamente. Ela relata que, quando do episódio do FUNDEF, ao buscar mobilizar sua categoria, foi publicamente interpelada pelo secretário municipal, então presidente do conselho desse fundo, que exigia que os professores não fossem "incomodados" e que não "admitia 
que se fizesse reunião" para discutir as suspeitas dos professores municipais. Ao ser repreendida, e sentindo-se infantilizada pela conduta tutelar do secretário, Dona Maria respondeu:

Olha, Professor, eu sabia que o senhor é uma pessoa muito atrasada com relação aos direitos das pessoas, mas nunca pensei que o senhor fosse tão atrasado ao ponto de pensar que o Sindicato, para representar a categoria no Conselho, para fazer alguma coisa, precisa de sua admissão. (Dona Maria, presidente do Sindicato dos Funcionários Públicos Municipais)

Curiosamente, essa mesma conselheira afirma por diversas vezes que os "conselhos não existem" ou "não funcionam". Ao ser indagada sobre o motivo de sua participação nos vários conselhos, respondeu:

É que sem eles (os conselhos) seria muito pior. [...]. No Conselho a gente discorda, diz que não quer que aconteça aquilo, que não assina, que não aprova. (Dona Maria, representante dos funcionários públicos municipais no Conselho Municipal dos Direitos da Infância e da Adolescência - COMDICA)

Penso cá com meus botões: os conselhos não existem? Como não existem? É verdade que são espaços híbridos, com representação paritária, funcionam com descontinuidades e com representantes, muitos deles sob estrita orientação do governo municipal, inclusive com presidência ou coordenação definida pelo prefeito. Mas estão ali a infernizar a gestão administrativa, a lembrar que há opiniões divergentes que têm o direito de se expressar. Ocorre que tanto os atores governamentais quanto os da sociedade civil parecem ter um modelo de funcionamento de conselhos referenciado em padrões de funcionamento do Estado racional, que deve desempenhar suas funções com eficiência e eficácia. Ao não se comprovar tal desempenho - que não se pode dizer seja de todo inadequado - conclui-se, apressada ou contraditoriamente, que não existem. Contraditoriamente porque, se referidos à prática observada, de freqüência e participação, não se pode dizer que não há um funcionamento. Insatisfatório, porém existente. Entendo, portanto, que os conselhos existem, embora funcionem com debilidades e com o trânsito dos atores que lhes impingem suas marcas. A esfera pública apenas se esboça.

Os trabalhadores rurais, perante a pretensão de ampliar sua presença no cenário político, enfrentam não somente as fragilidades que carregam historicamente em sua condição de classe destituída de direitos e desprovida de ganhos da "modernização" tupiniquim. Confrontam-se também com um Estado que, também historicamente, se caracteriza pelo desrespeito à autonomia das classes ou setores sociais com os quais interage, e busca trazê-los para espaços nos quais pode exercer seu domínio para, dessa maneira, dar continuidade à política tradicional que promove ganhos materiais e políticos às elites. Outras debilidades agregam-se a essa circunstância ou estrutura adversa, tais como: a pobreza, o analfabetismo ou o despreparo técnico para o exame de questões no cotidiano dos conselhos, por exemplo.

Tais considerações têm validade relativa também para explicar a experiência do homem simples nas associações de pequenos agricultores e no Sindicato dos Trabalhadores Rurais, posto que ambas as formas organizativas - criadas para cumprir objetivos referenciados na justiça social, na solidariedade e nos direitos - são freqüentemente "assaltadas" pelo Estado, desviando-as do desiderato que a história das lutas sociais lhes atribuiu. As associações, estimuladas ou não por governos - que interferem na vida comunitária, propondo a criação nas localidades onde ainda não existem ou influenciando na definição da pauta a ser discutida, condicionando a vida associativa aos projetos governamentais já definidos em outros locais - tecem muito lenta e silenciosamente os caminhos da autonomia política. Algumas delas, atentas à valorização dessa autonomia, caminham na direção da afirmação de projetos políticos elaborados no cotidiano das comunidades. É o caso da Associação Manos Kolping, que, em meio às limitações de várias ordens - ideológicas, materiais, culturais -, persegue 
sua utopia, aliando-se a setores dos movimentos sociais, como os funcionários públicos municipais e o Movimento dos Trabalhadores Rurais Sem Terra (MST), negociando com o Estado o acesso às políticas públicas. E lembre-se: negocia quem está, de alguma forma, mobilizado e, por isso mesmo, apontando para a existência de uma força suporte dos conflitos e das demandas encaminhadas.

Os trabalhadores rurais da Associação Manos Kolping, mobilizados inicialmente na comunidade em que moravam, influenciados pela Associação dos Pequenos Agricultores da Serra do Evaristo, criada em 1986, desistiram de ocupar a terra vizinha, em que muitos trabalharam desde a infância, pagando renda ao proprietário. Durante anos fizeram gestões junto ao governo estadual, uniram-se ao MST em acampamento em frente ao Instituto Nacional de Colonização e Reforma Agrária (INCRA) de Fortaleza, buscaram apoio do Sindicato dos Trabalhadores Rurais e, após avaliação coletiva das perspectivas e alternativas que se lhes apresentavam, decidiram, finalmente, comprar uma propriedade em município vizinho a Baturité. Com a intermediação da Arquidiocese de Fortaleza junto a duas agências católicas - a Manos Unidas (da Espanha) e a Obra Kolping (com secções na Alemanha e no Brasil), conseguiram recursos financeiros para complementar uma pequena poupança. Compraram, então, uma área de 360 hectares, divididos entre as 26 famílias participantes da mobilização. Criaram a Associação Manos Kolping e desde então passaram a produzir tanto em roçados individuais quanto em áreas coletivas.

As precariedades na Fazenda Manos Kolping assim denominada a nova comunidade - foram e ainda são muitas. Hoje, porém, as crianças com mais de sete anos têm transporte escolar; 23 casas já foram construídas com recursos da Reforma Agrária, que passaram a ser liberados a partir da articulação da Associação com o MST e órgãos governamentais; cada família tem o seu roçado, com algumas cabeças de gado e uma área coletiva para cabeças de gado individuais e coletivas; e mais de uma dezena de cisternas de placa para armazenar a água das chuvas em período de seca foi construída, permitindo, assim, independência gradual dos trabalhadores rurais com relação ao governo municipal, que agora só fornecerá água em carrospipa enquanto as cisternas não tiverem recebido as águas do inverno cearense. A Fazenda parece uma pequena vila. A primeira construção que se avista, ao chegar, é a sede da Associação, uma casa grande construída pelos seus membros, que aí ficaram morando, provisoriamente, enquanto as novas casas eram levantadas e a terra recebia as primeiras sementes.

É inegável que houve conquistas. A maior delas, inequivocamente, é o acesso à terra para trabalhar. A fala de José Carlos, dirigente da Associação, confirma minha percepção, ao opinar:

Eu acredito que conseguir terra para trabalhar aqui significou quase tudo. Porque a gente tem liberdade que não tinha para trabalhar, sabe. Meu grande sonho, que a gente nunca deixa de ter, porque enquanto há vida há esperança, é realizar tudo o que a gente tem vontade de ter aqui: saúde, educação, energia, que graças a Deus a gente já está conseguindo. (José Carlos, presidente da Associação Manos Kolping)

A terra de trabalho começa, assim, a cumprir sua função social. De "terra nua", propriedade capitalista sem exploração, que opera na economia capitalista como reserva de valor, foi transformada em "terra de trabalho" pelos trabalhadores. Terra que alimenta e produz riqueza com a incorporação do trabalho familiar. Terra que acolhe homens e mulheres, jovens e crianças, retirando-as de um roteiro previsível, anunciado pela hegemonia do latifúndio, que concebe a propriedade fundiária como "terra de negócio" (Martins, 1991).

Os homens e mulheres que percorrem as páginas deste estudo são, em sua maioria, trabalhadores e trabalhadoras rurais sem-terra ou proprietários de ínfimas parcelas que não lhes asseguram a sobrevivência familiar; trabalham, muitos deles, como diaristas em propriedades alheias, para reproduzir sua condição de agricultores. Todos, mesmo aqueles que possuem pouca terra, carregam o sonho da terra para trabalhar, e 
assim manter os filhos próximos de sua proteção, além de contar com essa força de trabalho.

Vejamos alguns depoimentos de trabalhadores rurais que revelam o sonho da liberdade e de construção de perspectivas de vida digna para a família. Comecemos pelo sr. Ziquinho, aposentado, não-proprietário, do Sítio São Pedro, que, meio desajeitado, entre o riso envergonhado e a alegria de sua esposa com uma conversa ao pé da porta, assim fala:

Tenho um sonho. É ter ao menos o que é da gente, sossegado. Eu trabalho, mas é meio assustado. Porque não sou dono da terra. Quando a proprietária [da terra onde trabalha] veio falar para eu comprar e eu disse que não podia, ela mandou eu arrancar minhas coisas, minha casa. Isso é que a gente fica pensando. (Trabalhador rural, 66 anos, sócio da Associação dos Pequenos Agricultores do Sítio São Pedro)

Matias, do Sítio Coió, arrendatário em duas, às vezes três propriedades, ri quando fala de seu sonho. Seus olhos lacrimejam e, tentando esconder a emoção na fala calma, nos dá seu relato:

Todo mundo tem um sonho. Eu pretendo, ainda, se Deus me proteger e me der sorte, comprar uma propriedadezinha pra eu, quando ficar velho e morrer, deixar meus filhos numa situação boa de trabalhar, pois eles são agricultores e gostam de ser agricultores. Isso era um sonho meu. Era, não. É. Ainda tenho essa pretensão, pra ver eles tranqüilos, criando e plantando, porque a gente gosta de criar e de plantar. Todos já são adultos. O que eu já passei... Eu nunca fiquei tranqüilo pra morar, trabalhar e fazer minha raiz. (Trabalhador rural, 48 anos, ex-diretor do Sindicato de Trabalhadores Rurais)

São os homens portadores de sonhos como os do sr. Ziquinho e de Matias que caminham pelas estradas pedregosas da Serra de Baturité para participar das reuniões das associações, dos conselhos ou do Sindicato. Levam suas demandas. Muitas vezes nem falam; aderem às falas de seus pares, indicando concordância com um aceno de cabeça respeitoso. $\mathrm{Ou}$ discordam, fazendo-se parecer distantes, em silêncio.
Há aqueles de temperamento mais aguerrido que disputam a palavra, que sugerem alternativas, questionando lugares instituídos. Fazem críticas à própria oportunidade de participação. Matias, por exemplo, diz que "participar é ajudar a fazer" e que muitas vezes a participação que se deu no Município "foi participação entre aspas".

A história da Associação dos Pequenos Agricultores do Sítio São Pedro é bem diversa da história da Associação Manos Kolping. A criação da primeira, por exemplo, é bastante recente e foi estimulada pela liderança do sr. Moura, que buscava responder à necessidade de organização das famílias em um espaço associativo reconhecido legalmente pelo Estado, seja no âmbito municipal, seja no estadual; o prefeito, por seu lado, incentivou e apoiou decisivamente a criação da Associação do Sítio São Pedro. O estímulo encontrava justificativa na seguinte argumentação: os recursos do Projeto São José, a serem pleiteados no CMDS, somente poderiam chegar à comunidade se formalizados em projetos, se elaborados por uma instituição de caráter associativo. A adoção de tal procedimento em todos os municípios do Ceará é decorrente da proposta de "gestão compartilhada" do governo estadual, que convocou a população à participação nesses conselhos (Jereissati, 1995). Tal exigência de criação foi acatada pelos prefeitos cearenses e pelas lideranças comunitárias. A partir desse impulso oficial, a maioria dos 184 municípios cearenses criaram os CMDS e as comunidades rurais criaram as suas associações.

Além dessa motivação de ordem governamental para a criação da entidade, o sr. João Moura e seus companheiros encontraram outra: enfrentaram certa dificuldade para conviver com os trabalhadores rurais da vizinha Associação dos Pequenos Agricultores do Sítio Correntes, entidade à qual alguns já eram associados. Assim, em 1998, criaram sua própria associação, com a finalidade de institucionalizar as demandas que deveriam ser feitas aos governos estadual e municipal. O ex-presidente da Associação conta que sua trajetória de participação teve início na Associação do Sítio Correntes. Foi aí que ouviu falar em 
"projetos", em conselhos. As palavras do sr. João Moura revelam que esse sentimento de "pertencimento" é componente indispensável para o aprendizado da fala, um dos "ingredientes" para a instituição da democracia. Diz ele:

A Associação é o caminho de todos. Você conversa o que sabe, conversa o que é. Não é conversa diferente. É tudo aquilo que você está sabendo: vou plantar meu roçado assim, vou plantar meu roçado amanhã... É aquilo que a gente "conveve". Ali, a gente tá aprendendo e tá ensinando, e cada qual tem vez. A pessoa mais tola que está na Associação, tem vez que tem questão tão brilhante que a gente fica impressionado com o que passa! (Sr. João Moura, ex-presidente da Associação dos Pequenos Agricultores do Sítio São Pedro)

Assim se referiu às reuniões das quais passou a participar, nos conselhos e na associação da própria comunidade, fundada em 1998:

Sempre dei muito valor à reunião porque reunião eu acho que é escola de quem nunca aprendeu nada, né? [...]. Até hoje, o que nós adquirimos é quase nada nestes dois anos. [...] mas hoje é diferente porque o prefeito não pode prender muita coisa, né, fica uma administração mais transparente; fica mais porque antigamente quem sabia o que existia? Ninguém sabia. Hoje em dia muitos não sabem, mas muitos já vão sabendo. Mesmo com as coisas que vão aí um pouco meio de banda, por aqui e por acolá, mas a gente vê transparência nas coisas. Porque não adianta negar, né? Você sabe que aqui e acolá a gente tá vendo alguma coisa. Eu mesmo não sabia nem o que era conselho, não sabia o que era administração municipal. (Sr. João Moura, ex-presidente da Associação dos Pequenos Agricultores do Sítio São Pedro)

As associações têm se constituído como estruturas institucionalizadas que fazem a ligação das comunidades com o Sindicato, com os conselhos municipais e com a administração municipal. Daí o sr. João referir-se à gestão municipal e aos conselhos, ao contato com o mundo da burocracia como um conheci- mento que passou a ter depois que as associações lhe deram visibilidade. Essa transparência e visibilidade de que fala o sr. João Moura, da Serra de São Pedro, certamente não têm a espessura daquelas a que se refere Wanderley (1991), para quem um dos atributos de uma gestão democrática e efetivamente pública é a transparência nas decisões, no oferecimento de informações e na alocação dos recursos, permitindo o controle social por parte de todos os segmentos sociais. Com certeza, a gestão pública em questão - a administração municipal de Baturité - não carrega os atributos pontuados acima.

Avalio, porém, que o sr. Moura possui a sua própria interpretação ou percepção do que é transparência - como diria E.P. Thompson -, pois é ele quem vive ou viveu situações que lhe permitem apreender a publicização dessa forma ou nessa abrangência. Sem querer incorrer na demagogia ou "empiricismo", mas querendo atribuir aos elementos teóricos expostos a função que aqui lhes cabe - de recursos que iluminam uma interpretação ou compreensão da realidade do homem simples -, a indagação a ser feita, então, é: qual foi a experiência do homem simples, como o sr. Moura, acerca do funcionamento do aparelho estatal, para que atribua tal importância ao conhecimento que dele possui, ainda que superficial, proporcionado pela vida associativa? Certamente, convívios democráticos não foram fartamente ofertados pelas gestões municipais de Baturité, e a história de vida deste homem simples nos autoriza a compreensão de que, por mais restrita que seja sua participação nos conselhos, esta é valorizada, pois lhe permite vislumbrar um conhecimento mínimo do trânsito de suas aspirações pelo aparelho burocrático estatal. $\mathrm{O}$ que se pretende com tal questão é destacar a dimensão pedagógica que a experiência participativa encerra, em que pese o alcance limitado do processo de publicização das decisões governamentais.

Passemos, agora, a examinar a experiência dos trabalhadores rurais em seu Sindicato. Ele movimentase em ritmo pendular na busca do cumprimento de sua real função, ora empunhando bandeiras e lutando por direitos, ora afogando-se em carimbos e cadastros. 
Esse dilema é característico de nossos espaços sindicais rurais, cujos percursos tiveram início nos anos de 1950 e 1960, quando foram criados no Nordeste, a partir de iniciativas de lideranças católicas ou comunistas que disputavam a hegemonia política junto aos trabalhadores rurais. Vale lembrar que no Ceará as ligas camponesas exerceram influência bastante reduzida, permitindo aos militantes do Partido Comunista Brasileiro (PCB) ou da Igreja católica amplo campo de intervenção política (Beserra, 1990). Assim, o Sindicato de Trabalhadores Rurais de Baturité foi criado em 1962, a partir da iniciativa de um senhor de terras, Coronel Ananias, fervoroso oligarca católico.

Após sucessivas eleições sindicais que instalaram na diretoria da entidade um representante do Coronel Ananias, conhecido no Município pelo seu paternalismo e clientelismo, somente em meados de 1980 o Sindicato de Trabalhadores Rurais de Baturité se desvencilhou da ligação estreita com a elite local, quando, então, os trabalhadores rurais elegeram uma diretoria claramente preocupada com a politização da vida sindical; uma politização que passou a se a produzir de forma débil, posto que a legislação sindical concorre sobretudo para a efetivação das práticas tradicionais de nossa cultura política. A ampliação da esfera pública pelo Sindicato implicaria, em tese, a implementação de práticas que viessem a assegurar direitos sociais - aposentadoria e outros direitos previdenciários -, assim como o direito à terra, sem enveredar a vida sindical pelas rotinas do trabalho burocrático-administrativo, função do Estado. Porém, uma ação ambígua e pendular acometeu a vida desse espaço associativo.

Uma expressão da prática pendular do Sindicato, anteriormente aludida, pode ser compreendida ao se observar o seguinte: em certos momentos, a diretoria do Sindicato parece privilegiar a mobilização social para o alcance de suas reivindicações; por exemplo, não empregando as energias associativas na valorização das novas institucionalidades, como a participação dos trabalhadores rurais nos conselhos. Assim, organiza e dirige mobilizações no período da seca, encaminhando reivindicações ao governo; participa de acampamentos e outras manifestações políticas, como o Grito da Terra e o Dia Internacional da Mulher, em frente aos órgãos públicos na capital do estado etc. Em outros momentos, em contrapartida, as malhas criadas pelo Estado - impostas pela burocracia do Instituto Nacional de Seguridade Social (INSS) e aceitas pelas lideranças sindicais, diga-se de passagem - provocam verdadeira acomodação ou captura desse espaço público às rotinas de preenchimento de cadastros e encaminhamento de processos administrativos. São rotinas não adequadas a uma entidade sindical, mas ao aparelho estatal. Tais circunstâncias tornam custoso o questionamento das condições sociais em que vivem os trabalhadores rurais; este, sim, uma prática propriamente sindical. Em outras palavras, a aquiescência do Sindicato dos Trabalhadores Rurais à imposição do trabalho burocrático dificulta a educação e a mobilização políticas. Coloca-se, atualmente, para as lideranças sindicais, o desafio da busca de alternativas para a autonomização da entidade na relação que mantém com o Estado.

No caso de Baturité, os trabalhadores rurais principalmente algumas lideranças, não todos - não estão alheios ao fato de que essa dinâmica pendular compromete a importância e a autonomia do Sindicato. Além da burocratização decorrente do fato de ter assumido atribuições estatais, outros problemas quase imperceptíveis são enfrentados pelo Sindicato. Já se impõe como questão, por exemplo, a necessidade de redefinição do espaço, nos seguintes termos: para ser público, faz-se necessário remover da vida sindical prováveis interesses particulares, não explícitos - como o apego à condição de assalariado em que se encontram certas lideranças ou o apego destas a um certo prestígio, ilusório talvez, com os sócios. Em resumo, segundo avaliação da própria diretoria sindical, é preciso que os trabalhadores rurais se desvencilhem de relações típicas de burocracias que se alimentam da despolitização de suas bases sociais.

$\mathrm{O}$ exame das experiências de participação aqui empreendido buscou oferecer um cenário no qual o exercício da política se faz tecido como uma trama de relações contraditórias e ambíguas; uma trama de 
práticas que afirmam direitos e práticas que os negam, traçando um processo de incontáveis idas e vindas, do fazer e do desfazer da política. A política e a esfera pública configuram-se como movimentos aproximativos, cuja dinâmica parece delinear gradações e estabelecer patamares que, logo a seguir, são desconstruídos por descontinuidades, descrédito ou pela instrumentalização de mecanismos participativos por governos municipais ou estaduais. A ampliação da esfera pública é, para o homem simples, uma árdua e lenta labuta cotidiana.

Oliveira, ao analisar a construção da cidadania e da democracia no Brasil, enunciou uma tese: é uma construção parecida com "trabalhos de Sísifo". Assim se expressa o autor:

Os esforços constantes e continuados dos dominados de toda espécie, para alcançar patamares mínimos de convívio democrático, esteios da figura insubstituível do Estado de Direito Democrático, são permanentemente destruídos pelo amplo leque dos dominantes, que utilizam para além dos códigos de sociabilidade anticidadão e antidemocrático, o poder estatal de forma implacável. (1998, p. 1)

Nesse dilema vivido pelo Sindicato, um aspecto que merece reflexão (e que se trata de questão substancial neste estudo) é o da reprodução, pelos trabalhadores rurais, de práticas tradicionais de nossa cultura política. Em minhas aproximações da vida sindical, em Baturité, tive a oportunidade de ouvir um curioso depoimento de um sindicalista que se destaca pela combatividade e pelo engajamento na política. É um depoimento ilustrativo da "cordialidade" característica de nossa cultura política. O sindicalista conta que, antes mesmo de se eleger vereador pelo Partido dos Trabalhadores (PT), foi solicitado para acompanhar ao INSS um trabalhador rural, filiado ao Sindicato, com a finalidade de facilitar as providências relativas à sua aposentadoria. Não se recusou a ir. Pelo contrário, procedeu como procedem outros dirigentes do Sindicato: acompanhou o sócio da entidade e intermediou a demanda de um direito social do trabalhador rural, a aposentadoria. Eis o relato:
Então, eu mesmo, como sou mais conhecido lá no INSS, acompanhei aquele sócio que estava com o processo emperrado, e com uma conversinha ali do lado, consegui apressar o negócio; e a aposentadoria saiu loguinho. (José Severino, diretor do Sindicato dos Trabalhadores Rurais de Baturité e vereador do PT)

A cordialidade aqui se reveste de militância, que encontra legitimidade nos favores prestados ao "cliente", desprovido de direitos. Assim, o associado do sindicato passa a contar com a intermediação do "companheiro". Será mesmo imprescindível o uso do expediente da aproximação afetiva e pessoal para lidar com demandas de direitos, reafirmando o "horror às distâncias" e a "simpatia pessoal" como traços característicos da sociabilidade brasileira (Holanda, 1984)? A observação me permite afirmar que, no Sindicato de Baturité, a prática do "jeitinho" é comum e não suscita maiores questionamentos; não causa estranheza aos sócios do Sindicato. Já se tornou banal e encontra-se incorporada ao dia-a-dia da vida sindical, sofrendo o que se pode denominar processo de naturalização.

A pesquisa verificou que as relações afetivas entre patrões e trabalhadores rurais, que obscurecem o conhecimento e a consciência dos direitos, encontram sua correspondência ou reprodução nas práticas sindicais. A política do favor ou clientelismo político, de tradição oligárquica, é, segundo Martins (1994), "antes de tudo, preferencialmente uma relação de troca de favores políticos por benefícios econômicos, e [...] essencialmente uma relação entre os ricos e os poderosos e não principalmente entre os ricos e os pobres" (p. 29).

É uma forma de dominação que eliminou da vida pública a população negra, os índios, as mulheres e os analfabetos. Essa "sociedade de história lenta", cuja modernização se efetivou e se vem efetivando nos marcos da tradição, e cujo progresso se dá nos marcos da ordem, convive com um passado recorrente, que constrange as mudanças sociais (Martins, 1994; Wanderley, 1996). Um passado que se mantém e rejuvenesce como prática porque é reposto não somen- 
te pelos ricos e poderosos, mas pelos pobres, integrados na política do favor ou da proteção.

Oliveira (1999) analisa que vivemos, nestes anos de neoliberalismo, um violento processo de privatização do público. E empenha-se em nos mostrar que uma leitura incompleta do processo de privatização do público compreende-o como se ele se efetivasse somente na dimensão das transações de privatização de empresas estatais ou do uso do aparelho estatal para atendimento de interesses privados. Em verdade, segundo Oliveira, essa é a forma mais visível de sua apresentação. Enfatiza que a privatização do público é mais do que isso: é o roubo da fala, é todo esse processo de destruição do espaço público, da exclusão das classes dominadas do discurso reivindicativo, e, no limite, sua destruição como classe. Não estaria, nesse gesto tão banal do sindicalista, acima relatado, um indício de que desse sócio do Sindicato dos Trabalhadores Rurais de Baturité foi roubada a fala? Não se reduziu, com a viciada prática da cultura do favor, tão naturalizada, a possibilidade de construção ou ampliação da esfera pública?

O tempo das experiências em curso, aqui analisadas, pode ser curto para que estejam consolidadas e para que se conclua de forma definitiva não ter havido a consecução ou o cumprimento das propostas enunciadas pelos governos, especialmente a redução das desigualdades e da pobreza com efetiva participação da sociedade civil. Tanto para o Estado quanto para a sociedade civil, a participação em parceria é experiência inédita na história do Brasil republicano. Há mesmo quem analise a participação direcionada para a construção da esfera pública como verdadeira refundação da República (Telles, 1994).

É possível afirmar que, não obstante o curto tempo histórico, os espaços públicos revelaram-se cenários nos quais ensaios de participação, isto é, de publicização, foram experimentados. Não cumpriram, todavia, o papel que, em tese, lhes estava destinado: o de instrumentos de mudanças sociais significativas (Gohn, 1989; Jereissati, 1995). Por exemplo, a proposta de criação dos Conselhos Municipais de Desenvolvimento Sustentável (existentes em quase todos os
184 municípios cearenses) e de associações, levada a termo pelo governo do Partido da Social Democracia Brasileira (PSDB) no Ceará, configurou-se, sobretudo, como instrumento de acomodação de conflitos, sugerindo o exercício não propriamente da política, mas da "polícia", que, nos termos de Rancière (1996), sugere a ocorrência de mera administração de interesses.

Uma avaliação mais radical diria mesmo que tanto a implementação de conselhos e de associações, propostos pelo PSDB cearense, quanto aquela dos conselhos setoriais ou gestores de políticas governamentais, prevista pela Constituição Federal de 1988, enfrentam um impedimento essencial, que é a resistência dos executivos governamentais em compartilhar decisões, em partilhar efetivamente o poder. E, do lado da sociedade civil, tal impedimento residiria na sua incapacidade de radicalizar com competência técnica e política o processo participativo oportunizado pelos espaços públicos até aqui construídos; incapacidade expressa em fatos largamente constatados pela pesquisa: a dificuldade de aprofundar debates, de questionar procedimentos, de estabelecer a pauta; ou seja, incapacidade de escapar da condição de mera executora de políticas sociais cuja elaboração e planejamento foram presididos pelo Estado, em outras arenas, não-participativas.

Há de se reconhecer, porém, que certa transparência foi alcançada pelos conselhos no âmbito municipal. Os conselheiros exigem prestação de contas pelo Executivo e divulgam suspeitas e questionamentos sobre o destino dado ao fundo público - seja encaminhando solicitação de apuração ao Ministério Público, seja participando de debates em rádios locais, como já foi abordado anteriormente. Sinalizam para o controle social como perspectiva plausível, como função que os conselhos tendem a abraçar com vigor.

As limitações de ambos os lados, do Estado (governos estadual e municipal) e da sociedade civil, tenderiam a se restringir caso as orientações políticas fossem alteradas a partir de novas eleições? Propostas de orçamento participativo ou de gestão democrática, cujo poder estivesse mais disseminado, baseado em decisões não-centralizadas, teriam capacidade de 
alterar os aspectos essenciais característicos das relações políticas no município em estudo? Estas inquietações merecem ser tratadas futuramente como questões de investigação, posto que a realidade já apresenta a necessidade de examiná-las. Setores da sociedade civil, em Baturité, dão sinais de inquietação quanto ao destino dos conselhos. Conversas informais indicam que, desde maio de 2002, uma tímida retomada dos conselhos vem sendo ensaiada; sem a iniciativa governamental, mas por iniciativa própria, algumas reuniões de conselhos foram realizadas, em especial do CMDS, cujos conselheiros parecem imbuídos de uma compreensão que valoriza esses espaços, a despeito de qualquer opinião que o Executivo municipal tenha sobre estes. Algo semelhante ocorre no campo sindical: a diretoria do Sindicato de Trabalhadores Rurais já vem procurando redefinir ações, em parceria com o INSS, que possibilitem dissolver os pontos de estrangulamento da vida sindical. Ademais, traçou um planejamento para 2003 que previu ampliação e politização da prática sindical.

Em suma, pergunta-se: uma nova orientação política, mais arrojada e comprometida com efetiva partilha de poder, desempenharia papel importante como estímulo à organização da sociedade civil, propiciando efetivas mudanças sociais e políticas? A pesquisa que ora se encerra fornece a seguinte pista: aos cidadãos não é indiferente o governo que "ocupa" o Estado; o compromisso com propostas democratizantes será identificado se vingar uma efetiva utilização de mecanismos de participação da sociedade. Suponho que uma nova orientação política, comprometida, então, com a construção desses mecanismos, pode ser um estímulo significativo para impulsionar mudanças materiais e culturais; afinal, o Estado somente pode ser reformado se incorporar as soluções elaboradas e construídas na sua interlocução com a sociedade civil.

De forma um tanto breve, pode-se dizer que o resultado do movimento dos homens e das mulheres na busca de direitos e de uma existência digna, entrelaçando-se com a prática do Estado nas suas diversas esferas, produz condições materiais, políticas e culturais que se distanciam dos patamares elaborados por sonhos e utopias, já tão cambaleantes em tempos recentes. O resultado que se apresenta é insuficiente aos olhos dos homens simples - homens e mulheres que se empenham na militância sindical ou comunitária, nas associações ou nos conselhos - face às necessidades de mudanças.

$O$ pequeno alcance das conquistas não apaga, porém, as aproximações gradativas a um modo de ser democrático. As relações sociais e políticas, hoje, são outras, mudaram qualitativamente. É certo que as marcas da tradição cordial, revestimento do paternalismo clientelista, renovam-se de forma insidiosa nas práticas sociais. Delas não escapam os espaços públicos, nos quais a política se realiza. No entanto, as relações de cordialidade não reinam absolutas no cotidiano da vida comunitária, aqui analisada. Em verdade, os espaços atravessados por toda sorte de relações - de amizade, de clientela, de desavenças e de pertencimento a uma comunidade, de solidariedade $\mathrm{e}$ de defesa de interesses particulares - tendem a se tornar públicos à proporção que os sujeitos vocalizam suas necessidades e interferem na definição de uma agenda mínima. Publicizam demandas, mesmo que palidamente, conformando novas institucionalidades que ora movimentam-se para legitimar, ora para contestar as políticas governamentais. Ademais, tecem com esse modo de ser democrático as linhas de projetos políticos, ainda sem acabamento perfeito (e os teremos, um dia, concluídos?), perseguindo sonhos, prováveis matérias-primas na reconstrução de utopias.

Nos embates que se estabelecem nesses espaços e que ampliam a esfera pública - e, nessa ampliação, o Estado se obriga a proceder de forma mais transparente e mais plausível ao controle social -, o legado mais significativo das experiências participativas é o aprendizado da cidadania. Aprendizado que só pode se consolidar com a aparição de homens e mulheres como sujeitos e não como vítimas, como cidadãos que tornam fala o que era ruído (Rancière, 1996), imprimindo sentido e marca social em práticas e em espaços outrora capturados pelo Estado de senhores.

Do exame das experiências no município de Baturité emergiu a mediação de setores da Igreja ca- 
tólica e de partidos políticos - estes, de forma mais difusa - como fator que contribuiu sobremaneira para que essas marcas se produzissem no cenário político local. No que diz respeito à Igreja e às agências católicas (como a Obra Kolping), é possível afirmar que intercedem no sentido de prover materialmente as comunidades - financiando projetos, capacitando e formando cidadãos - não sem antes desencadear um processo reflexivo no qual as noções de justiça e de direitos, orientadas pelo princípio da igualdade, tornam-se valores essenciais na prática cotidiana.

A política realiza-se, contudo, em vários âmbitos das práticas sociais. A análise das experiências participativas de duas comunidades rurais trouxe elementos que autorizam a seguinte consideração: o homem simples, o camponês, afirma politicamente seu projeto social - portanto, atua politicamente - quando se recusa coletivamente a abrir mão de sua condição camponesa . Permanecer no campo é um ato político, quer os sujeitos assim o entendam ou não. A recusa do destino proletário, no qual homens e mulheres descobrem-se divorciados de seus instrumentos de trabalho, é uma resistência praticada cotidianamente pelos personagens analisados nesta investigação. Uma recusa que não se faz com alarde ou grandes gestos de transgressão. Faz-se no silêncio da lida no campo.

Perseguir o sonho da terra de trabalho é uma lida quase insana. Significa a convivência com dilemas que, em momentos de penúria mais aguda, instalamse no cotidiano do trabalhador rural. Migrar ou enfrentar a seca? Unir-se aos outros em mobilizações em frente à Prefeitura ou à Secretaria de Agricultura ou permanecer sem perspectivas? Ser dono de uma terra própria, individual, ou de uma propriedade coletiva? Como "trabalhar liberto"? Este é um roteiro pelo qual passam os camponeses sem-terra e os que conquistaram um pedaço de terra para trabalhar com a família. Desse roteiro saltaram os trabalhadores rurais da Fazenda Manos Kolping, apoiados, principalmente, na organização sindical e na Associação de Pequenos Agricultores. O processo desencadeado pelo acesso à terra, longe de se apresentar como solução definitiva para as famílias envolvidas, propõe novas questões para exame e enfrentamento. Propõe, igualmente, questões àquelas famílias, como as do Sítio São Pedro, que não encontraram ainda um caminho para a realização do "salto próprio" do roteiro comum. A lição, ou melhor, o legado de todas essas pequenas experiências é o aprendizado da cidadania ou a ampliação da consciência dos direitos, que se faz com lentidão, silenciosamente. Mas se faz.

SÔNIA PEREIRA, doutora em ciências sociais pela Pontifícia Universidade Católica de São Paulo (PUC/SP), é professora adjunta da Faculdade de Educação da Universidade Federal do Ceará (UFC). Trabalha na linha de pesquisa Educação, Movimentos Sociais e Cultura Política, no Programa de Pós-Graduação em Educação Brasileira. Atualmente investiga o significado e a importância do analfabetismo e da alfabetização para os trabalhadores rurais organizados em associações de pequenos agricultores no Ceará, indagando se (e como) está se processando a construção do direito à educação no campo. Publicou: A participação social dos conselhos municipais no Ceará: oferta do Estado e conquista da sociedade civil (Revista Educação em Debate, FACED/ UFC, n 40, 2000, p. 80-92); A construção da esfera pública: a experiência dos trabalhadores rurais de Baturité (CE) em conselhos, associações e sindicato (CD-ROM do XI Encontro de Ciências Sociais do Norte e Nordeste, Aracaju - SE, em agosto 2003, 33p.). E encontra-se no prelo o artigo Contribuições teórico-metodológicas de dois historiadores: um possível diálogo entre E.P. Thompson e Sérgio Buarque de Holanda (Revista Educação em Debate, n 44).E-mail: soniapbarreto@ibest.com.br

\section{Referências bibliográficas}

BESERRA, Bernadete de Lourdes Ramos, (1990). Movimentos sociais no campo no Ceará (1950-1990). Fortaleza: Centro de Pesquisa e Assessoria - ESPLAR.

CARVALHO, Maria do Carmo A.A., (1997). Eppur si muove: os movimentos sociais e a construção da democracia no Brasil. Dissertação de mestrado. Programa de Pós-Graduação em Ciência Política da UNICAMP.

D'INCAO, Maria Conceição, ROY, Gerard, (1995). Nós, cidadãos: aprendendo e ensinando a democracia. Rio de Janeiro: Paz e Terra. 
GOHN, Maria da Glória M., (1989). Conselhos populares e participação popular. Serviço Social e Sociedade. São Paulo, s/nº, p. 65-89.

HOLANDA, Sérgio Buarque de, (1984). Raízes do Brasil. Rio de Janeiro: José Olympio.

JEREISSATI, Tasso Ribeiro, (1995). Discurso de posse do governo do Ceará. Fortaleza: Governo do Estado do Ceará.

MARTINS, José de Souza, (1991). Expropriação e violência: a questão política no campo. São Paulo: Hucitec.

, (1994). O poder do atraso: ensaios de sociologia da história lenta. São Paulo: Hucitec.

(2000). A sociabilidade do homem simples. São Paulo: Hucitec.

MINAYO, Maria Cecília de Souza, (1999). O desafio do conhecimento: pesquisa qualitativa em saúde. São Paulo: Hucitec.

OLIVEIRA, Francisco de, (1998). Entre a terra e o céu: mensurando a utopia. Trabalho apresentado no Seminário "Cidadania, Pobreza e Exclusão Social". Petrópolis: FINEP/NOVIB (digitado). , (1995). Neoliberalismo à brasileira. In: SADER, Emir, GENTILI, Pablo (orgs.). Pós-neoliberalismo: as políticas sociais e o estado democrático. São Paulo: Paz e Terra, p. 24-28. , (1999). Privatização do público, destituição da fala e anulação da política: o totalitarismo neoliberal. In: OLIVEIRA, Francisco de, PAOLI, Maria Célia (orgs.). Os sentidos da democracia. Petrópolis: Vozes/FAPESP, p. 55-81.
PEREIRA, Sônia, (2002). A contribuição do homem simples na construção da esfera pública: os trabalhadores rurais de Baturité - Ceará. Tese de doutorado. Programa de Estudos Pós-Graduados em Ciências Sociais da PUC-SP.

RANCIÈRE, Jacques, (1996). O desentendimento: política e filosofia. São Paulo: Ed. 34.

TELLES, Vera da Silva, (1999). Direitos sociais: afinal do que se trata? Belo Horizonte: Editora da UFMG. , (1994). Sociedade civil e a construção de espaços públicos. In: DAGNINO, Evelina (org.). Anos 90: política e sociedade no Brasil. São Paulo: Brasiliense, p. 91-102.

THOMPSON, E.P., (1987). A formação da classe operária inglesa. Rio de Janeiro: Paz e Terra. , (1981). A miséria da teoria ou um planetário de erros: uma crítica ao pensamento de Althusser. Rio de Janeiro: Zahar.

WANDERLEY, Luiz Eduardo W., (1991). Participação popular: poder local e conselhos. São Paulo em Perspectiva. São Paulo, Fundação SEADE, v. 5, no 2, p. 23-30. , (1996). Rumos da ordem pública no Brasil: a construção do público. São Paulo em Perspectiva. São Paulo, Fundação SEADE, v. 10, nº 4, p. 96-106.

Recebido em novembro de 2003 Aprovado em fevereiro de 2004 


\section{Resumos/Abstracts}

\section{Judith Kalman}

\section{El estudio de la comunidad como un espacio para leer y escribir}

La investigación reportada en este artículo responde a la demanda actual de construir propuestas de educación de adultos en general, y de alfabetización en particular, relevantes y pertinentes para los contextos cotidianos de los usuarios de estos programas. Define a la alfabetización como el aprender a manipular y utilizar el lenguaje deliberadamente para participar en eventos socialmente valorados. A partir de un marco teórico-metodológico cualitativo, presenta los hallazgos de un estudio de una comunidad marginada a las orillas de la Ciudad de México en el cual se exploró las oportunidades y escenarios locales para leer y escribir así como las situaciones cotidianas que favorecen la apropiación de la cultura escrita. Presenta una caracterización de cuatro diferentes espacios sociales comunitarios (la Iglesia, la familia, el puesto de periódicos), la historia reciente de su desarrollo y su ubicación en la vida comunicativa de los miembros de la comunidad. Concluye que para incrementar la calidad de la educación de adultos, particularmente lo referente a los usos y conocimientos de la lengua escrita, es indispensable no desestimar el carácter dinámico de los espacios de lectura y escritura.
Palavras-chave: educação de adultos; alfabetização de adultos; México

\section{A study of community as a space for} reading and writing

The research reported in this article responds to the current international demand that adult education and literacy programmes be relevant to the learner's immediate contexts. It defines literacy as the ability to manipulate deliberately and use written language in socially valued events. It presents the recent qualitative study of a marginalised community on the edges of Mexico City that explores the local opportunities and scenarios for reading and writing and the everyday situations that favour literacy learning. It includes a portrait of four of the community's different social spaces (the church, the post office, the family and the newspaper stand), their recent history, and their place in the language life of the community. It concludes that in order to improve the quality of adult education, especially those efforts related to literacy, taking the dynamic character of local reading and writing spaces into account is imperative. Key-words: adult education; adult literacy; Mexico

Sônia Pereira

A contribuição do homem simples na construção da esfera pública: os trabalhadores rurais de Baturité-Ceará
Analisa a experiência participativa do homem simples - o trabalhador rural sem-terra ou com pouca terra, posseiro ou arrendatário - nos espaços públicos como conselhos municipais, associações de pequenos agricultores e no Sindicato dos Trabalhadores Rurais de Baturité, município de 30 mil habitantes, no Ceará. A pesquisa parte de uma indagação básica: como o homem simples vivencia a política hoje? Entendendo política como transgressão, litígio ou mudança de lugares que se faz através da fala, da reivindicação, e examinando a possibilidade de construção da esfera pública, a pesquisa acompanha mais sistematicamente as experiências participativas de duas comunidades rurais, que se efetivam como oferta do Estado e como conquista da sociedade civil. A dinâmica participativa se estabelece movimentando práticas conflitantes que ora se caracterizam como relações democráticas e transparentes entre Estado e sociedade civil, ora como relações tradicionais, pautadas no autoritarismo e na cordialidade, traços significativos da cultura política brasileira. Embora as conquistas materiais das experiências associativas sejam reduzidas, aproximações gradativas a um modo de ser democrático são vividas, e essas, por sua vez, sinalizam para a produção de um legado: o aprendizado da cidadania e da consciência de direitos. 
Palavras-chave: trabalhador rural; participação; esfera pública

The contribution of the ordinary man to the construction of the public sphere: rural workers in Baturité State of Ceará

Analyses the participative experience of the ordinary man - the rural landless worker, lease-holder or tenant farmerin public spaces like municipal councils, associations of small producers and the Rural Workers' Trade Union, in Baturité, a municipality of 30,000 inhabitants in the State of Ceará. The research took as its starting point a basic question: how does the ordinary man experience politics today?

Understanding politics as transgression, dispute or the changing of positions, achieved by means of discussion and demands, and by examining the possibility of constructing a public sphere, the research followed systematically the participative experiences of two rural communities, which are characterised as State offers and as civil society conquests. The participative dynamic is established by involving conflicting movements which at times are characterised as democratic and transparent relations between State and civil society and, at others, as traditional relations based on authoritarianism and cordiality, salient features of Brazilian political culture. Although the material conquests of the associative experiences are limited, gradual approximations to a style of democratic being are experienced and these, in turn, signal the production of a legacy: the quest for citizenship and the awareness of rights.

Key-words: rural worker; participation; public sphere

Neusa Maria Dal Ri e Candido Giraldez Vieitez

\section{A educação do movimento dos sem-} terra
O Instituto de Educação Josué de Castro, que tem como mantenedor o Instituto Técnico de Capacitação e Pesquisa da Reforma Agrária e é vinculado ao movimento dos sem-terra, constituise em uma escola de educação média e profissional. O objetivo desse texto é o de expor os elementos educativos principais presentes na escola, bem como elucidar se a sua concepção educacional, que parece ser a mesma vigente nas escolas controladas pelo MST, contém elementos educacionais de interesse para as classes trabalhadoras em geral, do ponto de vista democrático e popular. A investigação revelou que o Instituto, estruturado e organizado de forma diferente daquela usualmente encontrada nas escolas oficiais, coloca em epígrafe categorias educacionais como a união do ensino com o trabalho e a gestão democrática compartilhada entre alunos, professores e funcionários.

Palavras-chave: educação; trabalho; autogestão

\section{Education in the Landless Workers'} Movement

The Josué de Castro Institute of Education, sponsored by the Technical Institute for Training and Research into the Agrarian Reform, which is associated with the landless workers' movement, provides both secondary education and technical training. The aim of this paper is to explain the principal features of this school, and to clarify whether its underlying educational premises, which seem to be similar to those extant in the schools under MST control, contain educational characteristics which are of interest to the working classes in general, from a democratic and popular point of view. The investigation showed that the Institute, whose structure and organisation differ from those commonly found in state schools, takes as its motto such educational categories as the union between education and work and democratic management processes in which students, teachers and school staff participate.

Key-words: education; work; selfmanagement

Danilo Romeu Streck

\section{O Fórum Social Mundial e a agenda} da educação popular

Realiza uma leitura do III Fórum Social Mundial, a partir da perspectiva da educação popular. Trata inicialmente dos objetivos e da dinâmica do Fórum para depois identificar temas que recomponham a agenda da educação popular. O primeiro deles refere-se à necessidade e às possibilidades de a educação popular ser pensada internacionalmente. $\mathrm{O}$ segundo trata da pluralidade de aportes e dos consequientes desafios epistemológicos e metodológicos. Por fim, são identificados alguns temas emergentes ou recorrentes, com base nas 1.286 oficinas oferecidas no Fórum.

Palavras-chave: Fórum Social Mundial; educação popular

The World Social Forum and the agenda for popular education.

This article presents a reading of the III World Social Forum, based on a popular education perspective. It deals initially with the goals and the dynamic of the Forum and then identifies themes which restructure the agenda for popular education. The first of these refers to the need and the possibility of popular education being discussed internationally. The second deals with the plurality of contributions and the consequent epistemological and methodological challenges. Finally some of the emerging or recurrent themes are identified based on the 1,286 workshops offered during the Forum. Key-words: World Social Forum; popular education 